\title{
Global overview on advances in structural health monitoring platforms
}

\author{
Esequiel Mesquita $^{1}$ (D) Paulo Antunes ${ }^{2,3} \cdot$ Francisco Coelho $^{5} \cdot$ Paulo Andréé, $^{2,4}$. \\ António Arêde ${ }^{1} \cdot$ Humberto Varum ${ }^{1}$
}

Received: 22 November 2015/Revised: 16 June 2016/Accepted: 22 June 2016

(C) Springer-Verlag Berlin Heidelberg 2016

\begin{abstract}
Advances in the development of sensors, data processing systems, and numerical models have motivated the implementation of structural health monitoring (SHM) specially focused on the assessment of structural safety. Thus, this work presents a literature review about SHM platforms, especially from 1993 to 2015. In this way, a short history review about the recent advances on SHM, mainly related with dynamic monitoring, was summarized, and a benchmark and the main guidelines related with SHM platforms were also included in this review. Some case studies are also described here. Special attention was given to SHM platforms, and a method for their classification (an extension of Rytter's method) is presented. In addition, experiences related with heritage constructions, specially focused on maintenance, were included in this work. In the final section, some observations are made about the new prospects for SHM. The recent advances on SHM platforms contributed to the development of adaptive systems and to the cost reduction of the monitoring systems
\end{abstract}

Esequiel Mesquita

e.mesquita@fe.up.pt

1 Department of Civil Engineering, Structural Division, Faculty of Engineering, University of Porto, 4200-465 Porto, Portugal

2 Instituto de Telecomunicações, Campus de Santiago, 3810-193 Aveiro, Portugal

3 Department of Physic, University of Aveiro, Campus of Santiago, 3810-193 Aveiro, Portugal

4 Department of Electrical and Computer Engineering, Instituto Superior Técnico, Technical University of Lisbon, 1049-001 Lisbon, Portugal

5 Department of Civil Engineering of Universidade Estadual Vale do Acaraú, Sobral 62040-370, Brazil implementation, allowing the increase of its application in real structures. However, the monitoring systems should be implemented, optimizing all the available sensing technologies.

Keywords Structural health monitoring · Platforms for structural monitoring · Heritage construction - Damage assessment $\cdot$ Smart structures

\section{Introduction}

\subsection{From construction to retrofitting: the change of focus}

Currently, the worldwide population is around 7 billion people and the predictions are that by 2100 , this number be of 11.2 billion [1]. In fact, the population growth will cause an increase in the need for housing. Nevertheless, considering the actual scenario of the climate conditions and its influence on the increasing probability of occurrence of natural hazards, this growth will be conditioned by the need for lower environmental impact new buildings and by the recuperation of heritage buildings, adapting them to the owners' needs. Consequently, new materials will be developed and introduced in the construction industry and maintenance approaches, new repair interventions methods for structural assessment will be implemented.

In emerging economies, the association between the development and introduction of new materials and the increase in the search of structural retrofitting, also motivated by compulsion for more competitive costs, tends to present a higher impact than in stabilized economies, with direct repercussions on building materials and constructive methods. Nowadays, reinforced concrete is the most 
employed material in the construction industry, but the forecast on worldwide concrete consumption points towards a decrease in its employment by 2100 [1]. If the concrete consumption decreases, especially in emergent countries like Brazil and South Africa, the number of new constructions also will decrease and the need for maintenance of the current structures will grow. This change of focus from "design of new structures" to "maintenance of the current constructions" in the construction industry is starting to be observed nowadays in the European community.

Therefore, the main issue is: how does the civil engineering sector intends to maintain the existing buildings safe and in good habitability conditions for the future generations? This question has motivated, essentially since the 1960 decade, the development of reinforcement techniques with lower impact for existing buildings and new methods of non-destructive assessment specially focused on the detection of damages in real time, the so-called structural health monitoring (SHM). In this context, the development of systems for the control, gathering, and management of data on structural safety parameters aimed at SHM is a new opportunity for researchers, builders, and construction companies to contribute to the development of "smart structures".

\subsection{Importance of SHM for structural safety maintenance}

Often, the structures are subjected to natural actions, and can also be subjected to the occurrence of environmental hazards and excessive loadings that were not considered during the design phase, compromising its structural safety. Nevertheless, the structural lifetime also depends on a series of other requisites, namely: materials quality, adequate design approach, adequate construction methods, execution, and existence of maintenance phases [2]. However, if the emergence of damage had been diagnosed early and if safety measures had been adopted, dramatic consequences, such as the resulting from the recent seismic events in Loma Prieta (1989), Northridge (1994), Kobe (1995), Chi-Chi (1999), and Emilia-Romagna (2012) could have been avoided or minimized [3]. Thus, it is correct to consider that after the construction stage, the structural lifetime is principally conditioned by the adoption of maintenance measures and the intensity of environmental actions. In this way, the SHM could be applied in the detection and diagnosis of damage in the early stages and in the prediction of structural risk.

Case studies on SHM [4-7], specially focused on damage identification and structural safety maintenance, for application on large infrastructures as well as on residential and commercial buildings, have become increasingly narrated in the literature. Examples of the decentralized systems and advances on the development of sensors are frequently introduced in the structural monitoring area [8-10]. Essentially, the innovation on SHM was initially motivated by the increase in the number of occurrences of natural disasters, such as earthquakes, hurricanes, cyclones, floods, and typhoons, according to Munich RE [11], survey has grown since 1980. In fact, the occurrence of a natural hazard in populated zones tends to present more dramatic losses, and this effect should be most intense if the affected zone presents a low economic development index [12, 13].

Annually, the worldwide monetary losses related to the occurrence of natural hazards are in the order of billions of dollars, and are deeply linked with structural and infrastructural damages. A survey report presented by Munich RE about global economic losses caused by natural disasters occurred between years 2010 and 2012 relates that in this short time, the losses were of US\$ 350,709 billions and it is expected that until 2015, the losses will be the highest ever recorded in world history [11]. In fact, the economic crises all around the world have often been initially motivated by the occurrence of environmental disasters [14] in opposition to economic and industrial development. Thus, considering that the rise in the number of natural hazards on vulnerable zones is centered in the global climate changes, global policies have been developed to raise sensibility to natural disasters, the Conference on Sustainable Development-Rio +20 [15], organized by the United Nations in June of 2012 in Brazil, being a prime example, and this endorses the relevance and need for innovative developments in structural safety maintenance.

Beyond natural hazard occurrences, the structures are subjected to other natural phenomena due to exposition to environmental conditions, such as corrosion, carbonation, and alkali-silica reaction, which also have an influence on accelerating material degradation, and, consequently, decreasing their lifetime (Fig. 1). From these, corrosion may possibly be the most evident phenomenon of material degradation in steel and reinforced concrete structures being accelerated essentially by the formation of chlorides or another inorganic salts. Hence, corrosion constitutes a global problem [16] that has mobilized the academic community to study its mechanisms of occurrence, catalytic agents, and methods of prevention (especially mixtures to concrete) and repair [17-20]. A survey performed by the Federal Highway Administration in the US demonstrated that there are 134,000 bridges, requiring immediate repair measures and 226,000 bridges presenting corrosion problems, resulting from environmental actions combined with a low frequency of repair proceedings [2]. Indeed, the structural assessment should not only include the structural parameters, but also consider durability 


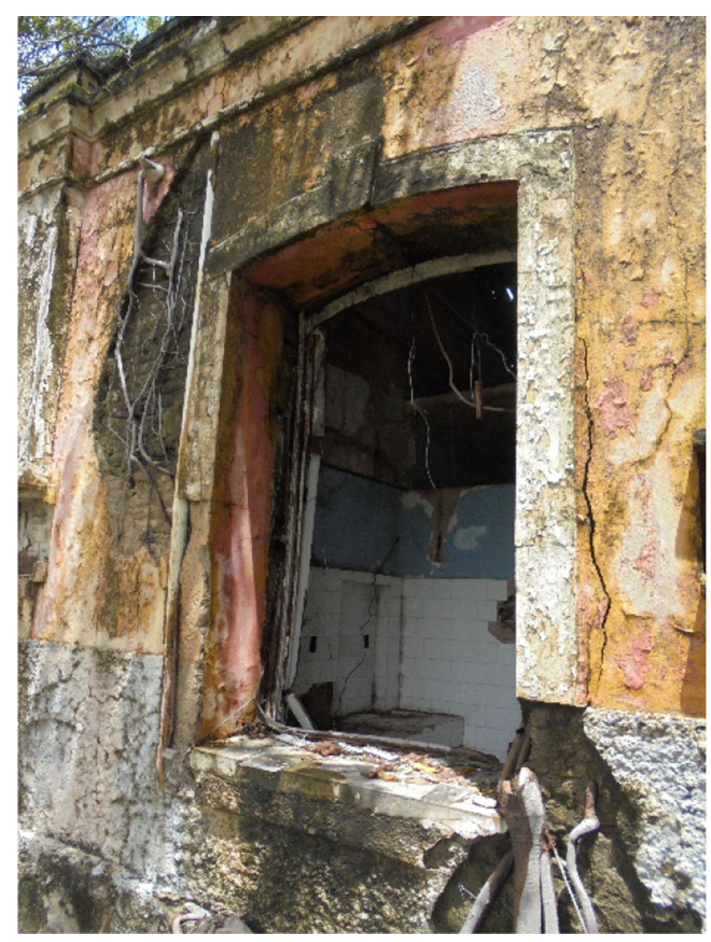

Fig. 1 Material degradation by environmental action

parameters, for a most effective evaluation with the purpose of offering data to a better structural characterization.

Actually, structural assessment is based on two distinct groups of data: (1) the information from visual inspection and (2) the data from experimental testing. Essentially, the visual inspection has been the initial step for the start of structural assessment, and the alert on damage emergence should be first noted by the own owners' observations. For structural behavior characterization, the employment of destructive test (DT) can be essentials; however, the new perspectives in SHM introduce the concept of "non-intrusive assessment" in the structural evaluation. Along this line, the number of the non-destructive tests (NDT), especially for in situ applications, has presented an expressive rise [21-23] motivated primarily by need of lower impact to construction, more competitive cost, and time reduction for data acquisition during the assessment process. In truth, the advances on non-destructive methods for structural assessment allowed the expansion of information about special constructions, namely heritage constructions, especially because these constructions present a large cultural value and their original characteristics should be preserved.

In complementary way, the advances on the sensing field allowed for the use of sensors in SHM applications with the multifunction of measuring, collecting, and transferring data. Today, the sensing systems present a decentralized distribution and their configurations can be framed according to the construction's needs to provide information for global structural characterization [9]. In fact, some working sensing systems could also be optimized for the information to be available in a virtual platform, allowing the remote access to the data [24]. This practice has been implemented with the aim of optimizing technical work for the structural assessment in real time [25]. However, the technological advances on SHM do not have as a goal to eliminate the human role in the structural assessment [26], but to offer a high performance tool for the evaluation of structures.

Differently from other works on SHM state-of-the-art (see [27, 28]), the present work approach is focused on issues related with heritage constructions (HC) maintenance, with special consideration to dynamic monitoring, and providing suggestions for ancient constructions preservation. This work provides a global overview on SHM latest advances, especially concerning the systems and platforms. An introductory section about the main historical advances is presented to offer a global perspective about the aims of SHM. Recent case studies related with heritage constructions and SHM were also included in this review. This work contemplates a literature analysis from 1993 to 2015, and the information was organized in six sections, namely: (1) Introduction, (2) Short history and recent advances on SHM, (3) Classification of the SHM systems, (4) Heritage constructions: a special case for SHM, (5) New perspectives for SHM, and, finally, (6) Conclusions. Thus, this literature review is expected to provide high-quality information for the development of SHM and, especially, to contribute to the multiplication of cases studies on SHM considering heritage constructions.

\section{Short history and recent advances on SHM}

\subsection{The initial history}

In the initial step of civilization, the human necessity of keeping in safety motivated the development of civil construction. However, due to the materials' own characteristics, environmental actions, and excessive loads, the construction degradation, evidenced by damage along the structure, made the need for structural assessment methods to emerge. In fact, the structural assessment is based on damage detection and its consequences for structural safety. Nevertheless, considering the various changes that can occur on a structure along its service life, it is necessary to delimit the comprehension about damages. Therefore, damages should be understood as the product of the harmful alterations in the material properties, due to physical, chemical, biological, or human interference, that can reverberate in changes on geometry and modal 
responses, affecting negatively the durability and structural safety $[27,29]$.

Damage can affect the structures in two ways, namely: producing linear or non-linear alterations on the structural behavior. The damages effects are characterized as linear when the structure presents a linear-elastic behavior and after the damage emergence, this behavior is not altered and the predictions about the behavior should be determined based on the previous behavior. Examples of these types of damages can be the effects from material degradation processes like rebar depassivation and concrete disaggregation. Nevertheless, when modifications occur in the structural behavior, namely from linear to non-linear, after the damage emergence, this effect can be classified as non-linear damage. Fissures and cracks are common cases of non-linear damages, for instance [27].

The implementation of the NDT occurred in largest scale since the 60s, with the development of the new methods of testing and its application in real structures was fundamental for the structural assessment evolution. In the 60 s decade, the modal parameters were introduced as a way of analyzing the structural state. However, the implementation of the structural monitoring was limited by the numerical models. One of the initial studies performed, which can be cited as a precursor of the SHM, was developed by Lifshitz and Rotem in 1969 [30]. In the Liftshitz and Rotem's [30] studies, vibrational techniques were employed in structural characterization by modal parameters, namely changes in the natural frequencies were used on damage detection [31].

In this way, the employment of a time history is of interest for the structural analysis, because it can provide data for a long-time period, considering different environmental conditions, variable loading situations, and damage evolution. To implement the monitoring, devices which do not introduce new damages on the assessed structure (non-destructive methods) were developed, as well static methods and its applications [32, 33], especially after 1970 [31]. However, the most innovative works were developed focused on to damage detection and assessment based on the vibration analysis, especially based on changes in the natural frequency [34-36]. However, the employment dynamic analysis also can give unspecific answers on structure behavior, this way, the adoption of static method can contribute for a most complete understanding on the current situation of the structure.

The basic principle for damage detection using the vibrational analysis is that the modal parameters of the structure (frequency, modal shape, and modal damping) can be defined through physical parameters (mass, damping, and stiffness), and any alteration in these physical parameters results in variations in the modal properties. Thus, the relations between the material's degradation and its influences on physical structural parameters allowed the development of a large quantity of studies and, as a result, some methodologies for damage detection based on vibration analyses were developed [31]. However, other non-destructive methods can also be used for damage characterization, such as the acoustic, magnet, radiograph, eddy-current, thermic [29, 37], and, more recently, the optical methods [38].

The analysis of the natural frequencies has been intensively studied to provide information about the initial moment of the damage emergence [29]. The initial advance for the use of frequencies changes for structural damage detection was given when was observed that, in structural elements, the occurrence of variations in the physical properties induced changes in the natural frequencies spectrum. However, the application of natural frequency analysis for damage detection has presented some limitations, especially to detection of the small cracks and fissures and the difficulty to differentiate the damages nature. Often, such methods provide a global analysis of the structure integrity, but do not give the location of the damage. Other recognized limitation is the environmental effect as the temperature or winds, for example, they cause changes in the structural frequencies and may result in incorrect interpretation about the damage occurrence. It is clear that this problem tends to be proportionally lower if the number of the monitored points is greater and the structural complexity is lower too [39, 40].

In fact, it is not totally understood yet what is the minimum magnitude of changes in the natural frequencies for the damage identification, but the most daring issue that has been motivating the studies development is: how does a specific damage can be identified based in the natural frequencies changes? To answer this question, basically, the works realized between the years 1975 and 1996 were developed around the phenomenal of natural frequencies changes as result of the damage emergence in structures. Nonetheless, it is not yet possible to establish a relation with this phenomenon and its influence on the modal parameters, but these works present a series of data about the structural behavior on different situations, namely: variable environmental actions, structural complexity, variable work ability, and different experimental programs. Nevertheless, the introduction of numerical methods and models for analysis of the damage emergence and the employment of the information available by the previous works have contributed for advances on the damage identification methods, being a step forward in the damage characterization, localization, and geometrical aspects, and also to the prediction about the lifetime and structural behavior [27, 37].

The growth of the assessment methods focused in the damage characterization and its variability has brought to 
Table 1 Damage identification methods classification proposed by Rytter (1993)

\begin{tabular}{|c|c|}
\hline Graduation & Objective \\
\hline Level 1 & $\begin{array}{l}\text { Damage detection (just provide information that the } \\
\text { damage is present) }\end{array}$ \\
\hline Level 2 & $\begin{array}{l}\text { Damage location (information about the geometrical } \\
\text { damage configuration and the specifically occurrence } \\
\text { location) }\end{array}$ \\
\hline Level 3 & $\begin{array}{l}\text { Damage characterization (provide information about the } \\
\text { intensity of the damage effects to structure) }\end{array}$ \\
\hline Level 4 & Lifetime prediction \\
\hline
\end{tabular}

light the emergence of the necessity for a classification system. Considering this question, in 1993, Rytter [31] proposed a classification to damage identification methods. The methods were organized according to the answer level, essentially centered in the damage existence, location, characterization, and prediction. The classification proposed by Rytter is presented in Table 1, as following.

Since the 70s, the development and application of the vibrational techniques based on natural frequencies changes were applied in the damage detection field, mainly in bridges and offshore structures. The methods of the structural assessment developed were based in linear behavior, due to the limitation imposed by the lack of numerical models. The results found through these methods in real structures provided informations about the damage presence, the location, and the damage characterization. Starting in the $80 \mathrm{~s}$ and $90 \mathrm{~s}$, the numerical models were implemented, primarily related with non-linear behavior, but the damage detection methods presented a low sensibility. The first sensors, focused in the detection of parameters for modal analyses, were developed and applied in the field; the processing system was also implemented. For the other types of structures, such as highways and buildings, the first SHM systems were introduced and tested [29, 37, 41]. The development of methods and devices focused on damage detection, and the integration between these devices with data processing systems and advances in the numerical analysis modified the practice of the structural assessment. Because of this advance, the initial concepts of the SHM emerged in the 90s [40].

Hence, structural health monitoring can be defined as a structural assessment process based on the measurements of structural responses, along of a determined time period, by use of non-destructive methods, essentially implemented with sensorial systems connected to a data central, capable of offering information in real time about damage emergence and characterization, in the most early ages, and to be able to collect information about the structural integrity during structure service life [26, 27, 40, 42]. In general terms, SHM is different from other structural assessment methods by the adoption of the NDT, comprisement of the monitoring system (sensors and data processing), possibility of the remote access, management of the regularity, and the duration of data acquisition [26].

The advent of SHM systems makes possible the data collecting in real time and its integration with structural analysis models and systems for prediction of the structural performance in uncommon situations, specifically when structures are subjected to unexpected loads, as natural hazard occurrences, and it should provide information about the necessity of a building evacuation [43, 44]. In addition, SHM may be applied both for local as for global damage detection, according to system complexity, but for this option, the circumstances of the materials degradation must be taken under consideration [40]. For a simpler global damage detection, commonly, the changes in structural behavior can be associated with development of fissures and, therefore, with changes in the modal parameters [45].

In 1996, Doebling et al. [37] presented the survey overview about the modal parameters used for detection, identification, damage characterization, and structural monitoring. Essentially, the authors showed experimental proceeds of SHM based on modal parameters changes for damage detection and pointed that the implementation of the algorithms should be made to minimize the dependence of the damage assessment process of the data set from the undamaged structure. In addition, it was observed the necessity for the development of methods that consider non-linear damage and studies about sensors quantity and measuring location should be performed in field for a most accurate analysis about the design of SHM systems.

In complement to the work presented by Doebling et al. [37], in 2004, a survey presented by Sohn et al. [27] reported a review about SHM between 1996 and 2004. In this survey, it was demonstrated the initial implementations proposed by Doebling et al. [37], in the field of the numerical modeling and sensitivity of the damage detection methods. The gradual decreasing of artificial excitation used in the modal analysis experiments, the widening of the field of application in engineering structures and the development of integrated systems for structural assessment were the main justifications of the advances verified. However, this review highlights the need for the development of comparative studies employing different methods of structural assessment and the implementation of the SHM systems in field, using decentralized systems in real time [37].

\subsection{Recent advances on SHM}

Essentially, from the year 2000, the implementation of systems and sensors employing optical technologies 
presented a new sort of advantages [46-51]. The optical fiber sensing techniques make possible the measurement of a high number of parameters with only one fiber cable, through the sensors multiplexing techniques [52]. Such sensors are also immune to electromagnetic interference, work at high temperatures, no electric power is needed at the measuring point, and have low size and weight, among other advantages. A search in the World Intellectual Property Organization-WIPO [53] in February of 2014, using the expression "optical fiber sensor", shows the existence of 473 registered applications focused on SHM.

Recently, some SHM monitoring platforms were implemented with devices to collect and control, and data processing systems working together, in the same framework, focused in the structural assessment. The necessity of platform development can be associated with the reduction of the time of assessment and global costs. This way, some platforms were developed and implemented centered to modal parameters monitoring [10,44, 54, 55]. One of the first patents related to SHM application was developed by the Hughes Aircraft Company, in 1993, with the register number US 518516. This patent reported an integrated system, composed by strain gauges and a device based on acoustic emission to detect crack.

When a search is realized employed the term "structural health monitoring" in WIPO [53], EPO [56], and United States Patents Trademark Office (USPTO) [57], 1707 patents can be found registered, namely: 1077 registers were founded in WIPO database, 177 registers in EPO database, and 453 in USPTO database. These registers were analyzed and classified in four different groups: (1) sensors, namely measurement devices; (2) methods, specifically numerical methods; (3) systems, that is integrated devices of sensors and data processing able to provide measurements and data processing around a specific monitored parameter; and (4) platforms to be precise more complex systems of assessment composed by association between systems of different parameter monitoring that aims the management of the data and an output about the structural safety. The results of this survey are presented in Fig. 2, where for WIPO, USPTO, and EPO, 48, 52, and $51 \%$ of the patent register correspond to sensors, respectively, while 28, 27, and $22 \%$ correspond to methods. For systems, the percentage of patent registers is $20 \%$ (WIPO), $22 \%$ (USPTO), and $25 \%$ (EPO), being only $2 \%$ (WIPO), $1 \%$ (USPTO), and $2 \%$ (EPO) of the registers found related with platforms.

The survey showed that the United States of America presents $67 \%$ of patent registers related with SHM in the World Intellectual Property Office (WIPO) and $48 \%$ in the European Patent Office (EPO). Nevertheless, the percentage of patents related with platforms is considerably lower

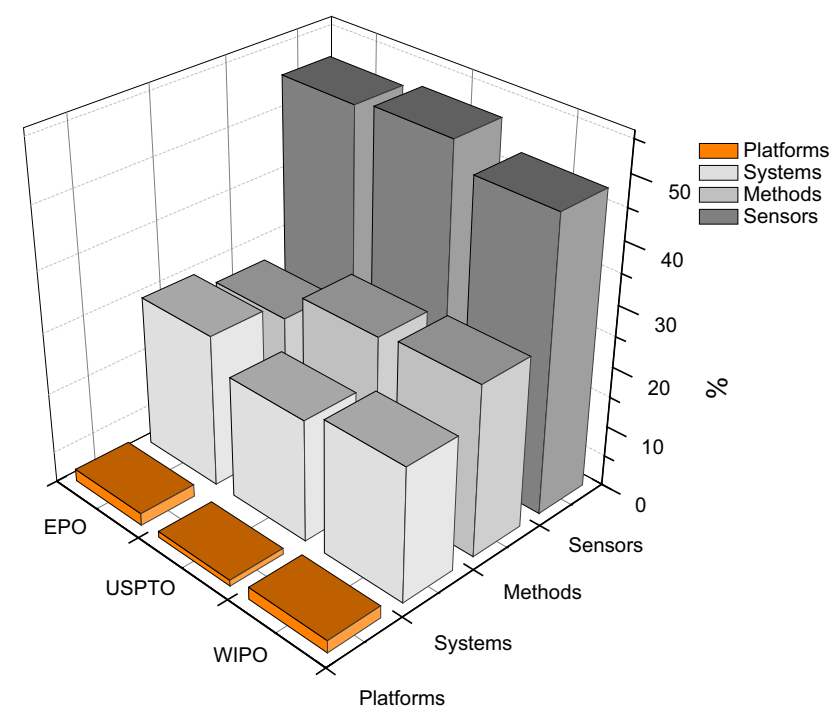

Fig. 2 Patents' register classification in sensor, methods, systems, and platforms

than the number of the registers related with measurement devices, methods, and processing systems.

Among the SHM platform registers, the patents US 20130132032 [58], US 20120123981 [59], CN 102034021 [60], US 20110035187 [61], US 20090083004 [62], US 20090048721 [63], and US 20070223003 were founded [64]. In general terms, those patents presented structural monitoring platforms composed by integrated systems, collecting and data processing systems, and focused to answer about the presence or not of specifics damages, namely considering modal parameters. Highlighting that the platform's component systems are active and the interaction between the owner and the system is limited to pre-defined parameters. In addition, it should be considered that the answer about structural behavior is focused around a specific point of measurement, and not by correlation between the modal and durability parameters. In addition, the answer level provided by the platforms can vary according to structure complexity and the owners' requests. This aspect is explored in Sect. 3 with recurrence to case studies available on literature.

One of the most innovative and recent patent register about structural heath monitoring platforms is the one with the reference US 20130132032 [58], providing a system able to employ a system of multiplexed sensors, for modal analyses, employing devices based on sonic, magneto elastic, electrical induction, piezoelectric, and fiber optical and nanotubes technologies, to provide data about the current structural safety. In this patent, the communication system was implemented using a wireless connection between the elements of the platform (sensors, storing system, processing system, and output). The sensors 
provide information about changes in parameters, such as strain, temperature, vibration, torque, angular rotation, bending, tension, and compression. The current structural behavior is presented by direct comparison between the values for pre-defined parameters and the measured ones.

Consequentially, the advances in SHM systems have imposed the emerging need for standardization methods aiming to compare the different methods of evaluation developed. Recently, Zhou et al. [65] presented a work about benchmarks and guidelines related with SHM methods. In this work, the authors present a "good practices guide" from the American Scientific Society and guidelines for testing methods standardization from the experiments combining numerical modeling in a steel structure, performed by [66], for damage detection on a full-scale structure. Linear analysis and posterior non-linear analysis were carried out focused to global characterization by modal response.

The guidelines reported by Zhou et al. [65], including SHM benchmarks are:

- Guidelines for structural health monitoring, reported by ISIS Canada in 2001 [67];

- Monitoring and safety evaluation of existing concrete structures, presented by Bergmeister et al., in 2002 [68];

- Development of a model health monitoring guide for major bridges, presented by Aktan et al., in 2002 [69];

- Mechanical vibration-evaluation of measurement results from dynamic tests and investigations on bridges, ISO, in 2004 [70];

- Guideline for Structural Health Monitoring, introduced by SAMCO, and reported by Rucker et al., in 2006 [71];

- Guideline for the Assessment of Existing Structures, presented by SAMCO, and reported by Rucker et al., in 2006 [72].

Most recently, Daum et al. [73] presented the Guideline for Structural Monitoring. In this work, beyond the stat-ofthe-art review about SHM, some benchmarks are presented specially related with SHM systems implementation.
In monetary terms, SHM systems implementation still represents a high cost of investment; however, it can produce a significant return in terms of the maintenance optimization, structural failures detection in early ages, equipment, and structure losses, and most important avoiding human injuries or fatalities [74]. Nevertheless, the SHM systems cost has been decreasing, especially by the constant development of lower cost sensors and techniques [75], [76].

Another important advance for SHM application, especially on full-scale analysis, was the development of minimization of environmental effect to data collected, as OMA techniques for instance (see [77, 78, 79]).

\section{Level responses of the SHM platforms}

Considering that a wide diversity of methods and measurement devices for SHM have been developed, especially linked with SHM platforms, it is recommended that the owners, as well as the design and installation personnel, take some time to consider the answer level necessary for that SHM system to be efficient and cost effective.

In fact, the sensing system configuration of the SHM platforms can change according to each construction, but it was observed that the level of damage detection monitoring required by the owners did not present deep changes. Therefore, platforms can be organized according with the specificity level of the answer provided. Therefore, the present work introduces a method of classification for SHM platforms (Table 2), that can be understood as an extension of Rytter's method [31].

In subsections 3.1, 3.2, 3.3, 3.4 and 3.5, and considering the classification method previously mentioned, some already reported studies were re-organized. The reference to the platforms application in the survey performed in this work had the sole propose of illustrating the current knowledge; therefore, only the main registers were discussed. Moreover, the systems' configuration and the results are also summarized and included. The objective of these subsections is to provide an exemplification on the

Table 2 Method of classification for SHM platforms based in the answer level

\begin{tabular}{|c|c|c|}
\hline Level & Aims & Provide information about \\
\hline 1 & Damage emergence & Damage identification \\
\hline 2 & Damage location & Damage emergence and location \\
\hline 3 & Damage characterization & $\begin{array}{l}\text { Damage characteristics, as type, intensity, and geometry, in addition to the information described in the } \\
\text { above-mentioned levels }\end{array}$ \\
\hline 4 & $\begin{array}{l}\text { Structural risk } \\
\text { characterization }\end{array}$ & The structural risk in the current state, as well the information described in the previous levels \\
\hline 5 & $\begin{array}{l}\text { Structural lifetime } \\
\text { prediction }\end{array}$ & $\begin{array}{l}\text { The structural lifetime considering the current structural state, in addition to the information related in the } \\
\text { above-mentioned levels }\end{array}$ \\
\hline
\end{tabular}


employment of the classification method introduced by this work.

\subsection{Level 1}

The first step of the damage detection methods is to recognize changes in the active forces as an indication of the damage presence. A large quantity of studies were developed, such as in $[39,40]$, and references therein. However, to provide a recent case study about damage detection Razi, Esmaeel and Taheri [80] improved a vibrational method employing piezoelectric sensors to monitor a steel pipe. The results showed that the vibrational method can be successfully employed for damage detection and that the employment of wireless monitoring system in real time can be a good alternative for damage detection in the most early age.

Sequentially, a study developed by Bandara et al. [81] aiming non-linear damage detection using natural frequencies change was presented. In this study, the authors introduce a neural network method for damage detection and employ data from a three-story bookshelf structure at the Los Alamos Laboratory for validating the new damage detection method. Beyond the detection of damage, the method also allowed the assessment of the damage level. Therefore, this method can be an important tool for nonlinear and light damage detection.

While both SHM platforms presented by Razi et al. [80] and Bandara et al. [81] were built focused to solve the same problem, they differ in terms of the technology used. The first introduces a concept based on the vibration analysis monitoring and its data analysis depends on a technical group experiences. In the second case, the SHM platform employs an artificial neural network for the data processing, collected by SHM platform. However, other data processing methods can also be successfully used, such as wavelet, proper orthogonal decomposition, and auto-regression. Essentially, both technologies can be applied in the same problem solving, namely damage detection in the early age; however, the field application is directly related with the level of automation required by monitoring system.

\subsection{Level 2}

Naturally, Level 1 platforms evolution is likely towards the damage location. Nie et al. [82] introduced a new parameter for damage detection based on changes on the phase of the vibration signal and the damage location is determined using a derivative from vibration time-history. The sensing system was composed essentially by strain gauges. Numerical modeling and experimental tests were carried out on an arch structure for demonstration, the method described can be applied for single- or multi-damage location. The results showed that this method provides information about the damage emergence and location, even when the damage emergence is far away from the measurement point. Beyond the damage detection, the data processed allowed to follow and monitor the damage progression.

A suitable method for local damage detection in large polymeric structures is presented by Naghashpour and Van Hoa [83]. In this work, an epoxy resin is modified by dispersion of multiwalled carbon nanotubes $(95 \%$ of purity, diameter between 2 and $20 \mathrm{~nm}$, and length from 1 to $10 \mu \mathrm{m})$. For large composites plates, with incorporated nanotubes, the electric properties are unique and those can be used as sensing devices. The damage detection was based on electrical measurements, specifically the fourprobe method. The advances on the platform included an increased performance, allowing minimal damage detection and real-time monitoring. In the same line of work, recently, D'Alessandro et al. [84] presented a smart cement for structural health monitoring based on nanosensors (carbon nanotubes), providing information about the mechanical deformations through changes in the electrical resistivity.

The SHM platforms presented by Naghashpour and Van Hoa [83] and D'Alessandro et al. [84] present some advantages relatively to the one developed by Nie et al. [82], as, for example, a most distributed and lower intrusive sensing system. However, the use of devices that can notice changes in the materials electrical properties can be less interesting, if the material durability is considered, as for example, on materials exposed to corrosive environments. Therefore, this technology is more restrictive than the SHM platform developed by Naghashpour and Van Hoa [83]. Nonetheless, if used in a combined form in the same global monitoring system for all the building components, the probability of early damage occurrence detection in a large area of the material surface will be high.

\subsection{Level 3}

The evolution and continuous implementation of monitoring devices and methods allowed Hosser, Klinzmann, and Schnetgöke [85] to correlate SHM data with a probabilistic model in a pre-stressed bridge element. The authors demonstrated, and described, the complete process of integration of sensors and probabilistic models, and the use of SHM data for damage characterization.

Rodrigues et al. [43] implemented and tested a monitoring system in a concrete bridge, Lezíria Bridge (Portugal), using optical fiber sensors. In this study, several sensors located in the structure surface and embedded in the structure were used. Two new transducers based in fiber 
Bragg grating (FBG) technology were introduced, and all the sensors implementation steps are described. They demonstrated that it is possible to use measurements in normal traffic conditions as excitation, and to establish an accurate prediction model around the deformed shape evolution.

The main difference between the two SHM platforms presented above is related with the implementation of the sensing system. The work presented by Rodrigues et al. [43] can be more attractive if a large number of sensors are needed to be used, due to the fact that the optical sensors can be multiplexed into the same fiber cable, adding to the fact that they are not susceptible to electromagnetic interferences. These two characteristics can be of particular interest when a complete structural characterization is required, due to cost reduction of sensor multiplexing. However, the system presented by Hosser, Klinzmann, and Schnetgöke [85] provided information about the interaction between the sensorial and data processing systems, also considering a reliability method for structural characterization.

\subsection{Level 4}

In 2010, Yi et al. used the dynamic response of the Dalian BeiDa Bridge (China) with frequency vibration measurements within an SHM system with the employment of a real-time kinematic (RTK) global positioning system (GPS) [86]. The ambient vibration measured by the accelerometers was used to improve the numerical model proposed in the work. The authors concluded that this system is an alternative for the conventional methods of structural monitoring, providing indicators that can be used for structural risk prediction.

With a similar method, Zhang et al. [87] reported a case study using optical fiber sensors for SHM on a simply supported reinforced concrete T-beam bridge, during dynamic and static loads aiming to identify the better moment for rehabilitation. The optical sensors employed were based in FBGs and Brillouin optical time domain reflectometry (BOTDR). The structure was submitted to dynamic and static testing, and the collected data were used for numerical simulation and model calibration, and finally, the proposed model was tested. The failure prediction evaluation results from the proposed numerical model showed a suitable degree of precision; however, the stiffness and non-linear analysis parameters should be improved.

In 1997, the Tsing Ma Bridge (Hong Kong) was equipped with an SHM platform aiming to collect data for structural risk characterization. The bridge was instrumented with 282 sensors and the real-time collected data allowed the structural assessment under natural and service conditions. In addition, similar SHM platforms were also implemented by the Highways Department of the Hong Kong Administrative Region on Kap Shui Mun Bridge, Ting Kau Bridge, Western Corridor Bridge, and Stonecutters Bridge with the same objective of structural risk monitoring and characterization [88].

Structural health monitoring platforms included in Level 4 present efficient communication systems, essentially based on wireless communication. In addition, the structural risk assessment considering the structural behavior under environmental and service conditions is a tendency for this type of platform, as can be seen in Yi et al. [86] and $\mathrm{Ni}$ and Wong [88]. However, the concepts developed by Yi et al. [86] combine technologies aiming to decrease the number of sensors used, such as GPS technologies, and for this reason, it might be more attractive for large structures or when a high number of sensors are need.

\subsection{Level 5}

In Runyang Suspension Bridge (China), the effect of the ambient temperature and the increase of vehicular traffic (loading) for fatigue were studied by Guo, $\mathrm{Li}$, and Wang [89]. The structure structural safety and fatigue were predicted by the numerical analysis (finite element model) based on the data collect by field application.

Other example of SHM platforms, that can be included in the Level 5, was demonstrated in the Canton Tower, situated in Guangdong, China. Canton Tower is constituted by a concrete-steel structure with a main $456 \mathrm{~m}$ tall tower. The sensorial system was composed by 800 sensors for 16 types of different parameters analysis. The results have shown that the implemented system provides accurate data (with GPS measurements and synchronization) about the horizontal displacement and, consequently, can be used as an alternative method for this type of assessment. In addition, the temperature influence in the tower horizontal displacement and the collected values were also used to predict the structural behavior until failure. The error analysis of the sensors system implemented was also verified to be higher than the error values checked by GPS measurements. Therefore, in this work, the authors had demonstrated the use of a large number of synchronized sensors working for SHM, but highlighting the necessity of a data processing implementation for lifetime prediction [25].

Currently, the reliability analysis is an important tool for structural safety assessment, especially for employment on areas with high environmental hazard incidence or probability of occurrence. SHM platforms combining a lower, as possible, number of sensors, and allowing the prediction about the structural risk based on dramatic natural scenarios, are the most attractive, as related in Xia et al. [25]. 


\section{Heritage constructions: a special case study for SHM}

Considering the SHM above-mentioned studies, the HC special case had not been addressed yet, dissimilar from other large structures, such as bridges and tall buildings. Consequently, this gap existence discloses the development necessity of specific studies on HC structural behavior, improving the knowledge on this special and very important group of structures, and, consequently, adding the need to develop new adequate assessment methodologies, tools, and devices for the real-time safety analysis.

Heritage constructions can be assigned as a special case, because they are structural systems different from the current ones, with complex behavior that often cannot be assessed or understood through the current codes, standards, techniques, or devices.

The International Council for Research and Innovation in Building and Construction (CIB) in its publication number 335 defines $\mathrm{HC}$ as any existing civil engineering construction that presents an elevated cultural value to the community around it. Cases of application of SHM in HC are, especially, interesting, from the techno-scientific perspective, due to the importance of this type of structures for the community (Fig. 3). Essentially, evaluating a $\mathrm{HC}$ is a difficult task due to the need for classification of the cultural value and comprehension about the important occurrences (natural or human) that the structure is submitted during its lifetime, especially how time-expressions should be conserved and how restoration should occur. For such cases, it is important to highlight the limitation around the assessment method in most $\mathrm{HC}$ cases that are limited to use of non-destructives techniques. The CIB publication 335 recognizes the necessity of collecting information about the structural time-history of $\mathrm{HC}$, highlighting that often no information is available [90].

The structural time-history objective is to offer information about the construction materials, safety parameters, natural actions, human interference, damage emergences, pathologies, structural parameters, and any type of constructive modification, to take action on preventive measures to maintain the structural safety. In addition, data from numerical modeling can be included in such reports as a method to improve the time-history.

An analysis of 50 reports executed between 2000 and 2015 by the Instituto da Construção (Civil Engineering Faculty of the University of Porto) on HC builted in the time period comprised between the XVI and XX centuries (32\% between $\mathrm{X}$ and $\mathrm{XV}$ centuries, $64 \%$ between XVI and XVIII centuries, and $4 \%$ between XIX and XX centuries) showed that a visual inspection was included in $100 \%$ of the assessment processes and only $58 \%$ of the $\mathrm{HC}$ presented any document with constructive information about the HC. The reports also showed that experimental tests were performed in $12 \%$ of the $\mathrm{HC}$, and in only $8 \%$ of the assessment was performed with recurrence to SHM techniques. Concerning to damage analysis, walls and arches are the most affected elements, essentially 80 and $58 \%$, respectively. In addition, the presence of damage on floors and columns was observed in 20 and $10 \%$ of the cases, respectively. It was also perceived the presence of cracks in $85 \%$ of the cases and in $70 \%$ of the buildings, some displacements were noticed. Humidity related damages were observed in $60 \%$ of the $\mathrm{HC}$ assessed. The complete information on this analysis can be seen in Fig. 4.

Considering the necessity for organized information regarding the inspections on $\mathrm{HC}$ and the structural timehistory, recently, a maintenance guide focused to $\mathrm{HC}$ was presented by Tavares, Costa and Varum [91]. In this work, the authors present a checklist of the main activities that should be realized during the inspections organized by aim of the inspection, measurements, inspections regularity, and persons responsible by each listed action.

Most of the $\mathrm{HC}$ monitoring experiences reported in the literature are related with the modal parameters analyses, in essence by changes in natural frequencies. Abruzzese et al., in [92], presented a wireless system focused on the management of the structural safety when a structure is
Fig. 3 Examples of important HC: a Porto historic downtown and b Coliseum, Rome, Italy
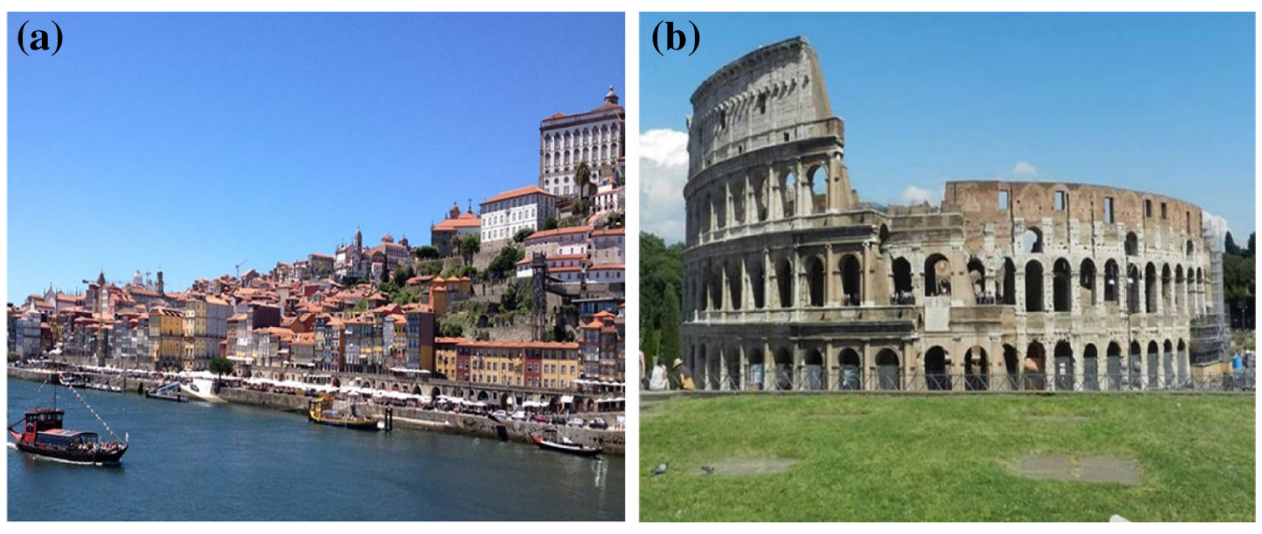
(a)

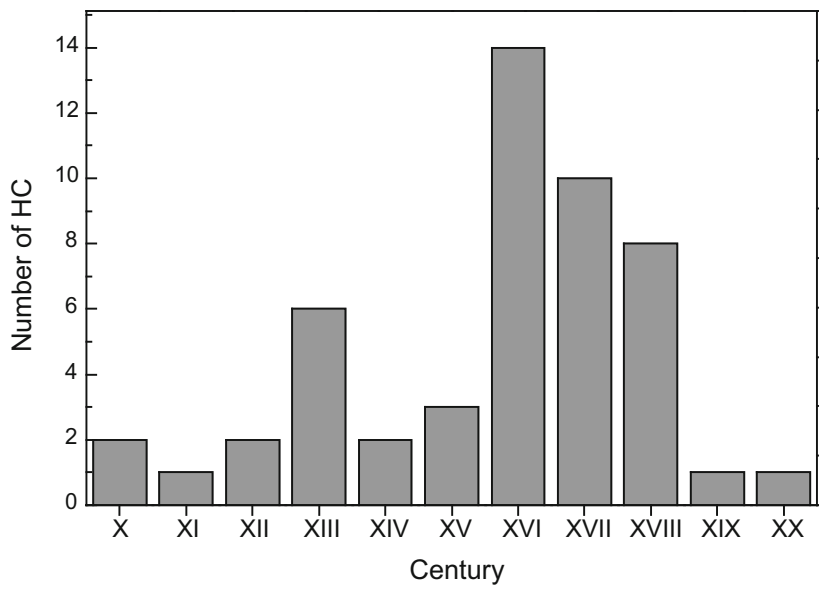

(c)

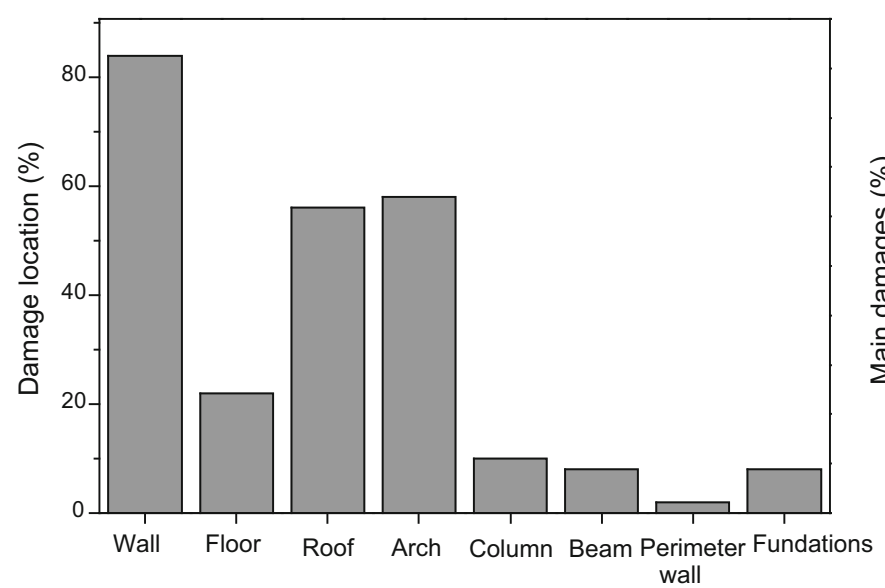

(b)

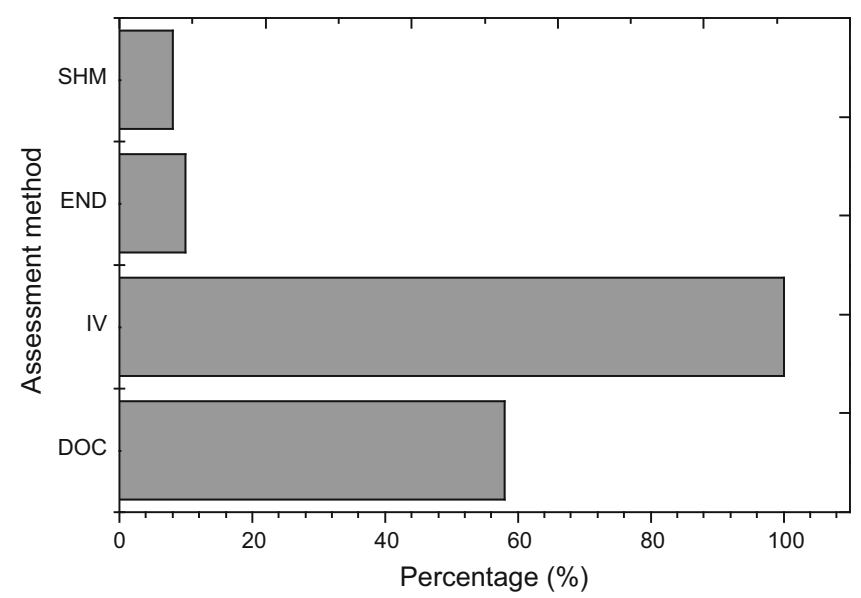

(d)

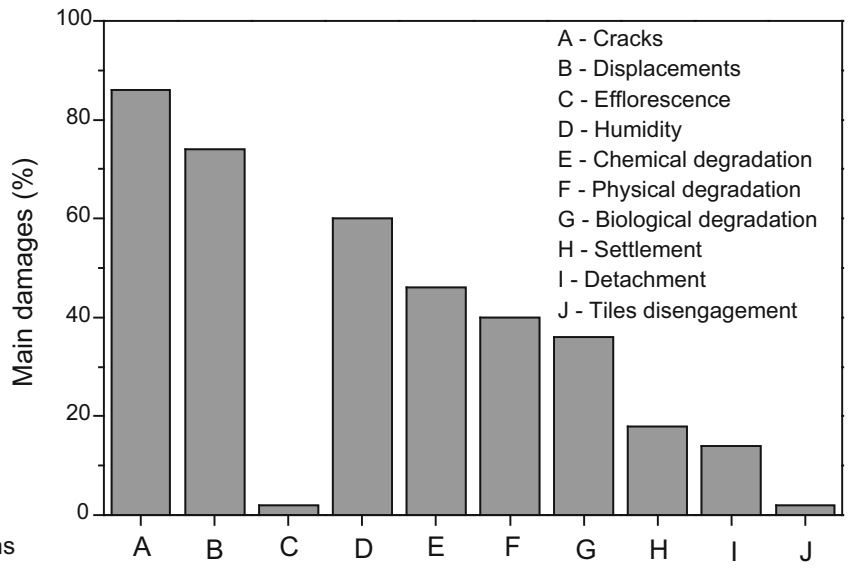

Fig. 4 Characterization of the HC analyzed: a construction age, $\mathbf{b}$ main assessment methods, $\mathbf{c}$ main buildings components affected by damages, and $\mathbf{d}$ main damage founded

succumbed to a natural disaster, like an earthquake. The dynamic characterization of an historical tower was done, and the data were used in a computational simulation. The data acquisition system was essentially composed by accelerometers linked wirelessly to a signal processing module central station. In fact, in a real disaster, the changes in the natural frequency showed similar values to the ones originated by the computational simulation. An alarm was implemented that can alert the owners about the structural collapse eminence. Similar works were also presented in [93] and in [94].

Another important case of heritage construction monitoring was presented in [95]. In this work, a construction built in the centuries XVI and XVII was also monitored. For assessment process, initially, a visual inspection was carried out and the main damages were identified. The authors agree that a preliminary inspection is necessary to an initial evaluation about the structural risk assessment and to the definition of the monitoring system. To provide information about the best location to the sensors installation, a numerical modeling was done and the high-risk zones were identified. Essentially, the monitoring system measured displacements (crack evolution) by transductors placed along the structure, temperature variation, and vibration to estimate the natural frequencies evolution due the damage presence. The considerations about the proceedings of HC assessment, above mentioned by [90] and [91], have been followed by the technical and academic communities.

Nevertheless, beyond the modal parameters analyses in the structural safety assessment, especially in HC, the material degradation should also be considered in the measurements [90] to provide predictions about the life expectancy and local damage emergence, for reinforcing measures adoption. It was shown in [27] that the structural analysis only based in modal parameters chances does not allow a significant identification about the zone affected by the damage. Nevertheless, the ideal location for sensors 
positioning will have a better performance if based in a preliminary modeling, focused into the identification of the fragile zones.

Recently, 30 case studies on rehabilitation of $\mathrm{HC}$ developed between 2003 and 2012 by Instituto da Construção and Faculty of Civil Engineering of the University of Porto were organized and presented by Costa et al. [96]. In fact, the importance of structural monitoring systems for structural assessment is highlighted along the related cases, where special attention is given for non-destructives techniques. In addition, this work demonstrated the University of Porto experience on SHM methods for safety assessment, contributing for knowledge dissemination about the good practices on $\mathrm{HC}$ assessment.

\section{New perspectives for SHM}

The recent advances on SHM show that the monitoring systems can be functional for different circumstances of structural assessment. The sensors development and monitoring techniques had been improved and the inclusion of the durability parameters has been an upgrade, to promote a better damage characterization and an accurate structural lifetime prediction [97]. A significantly quantity of optical sensors has been developed and implemented, motivated by the better signal to noise ratio, good sensitivity, electromagnetic interference immunity, multiplexing possibility, low size and weight, robustness, low attenuation on remote monitoring, and no electrical power needed at the measuring point, among other advantages [52, 98, 99]. Thus, such sensors can potentially provide an optimized sensing system with higher performance. However, the emergent sensing systems should be able to collect data and interact with the available and older installed technologies, for example, video cameras, electronic sensors, and environmental or climatic predictions available from web platforms. In addition, the owners should also be included as part of the sensing system due to the fact that they can contribute for the structural time-history composition over photos register and observations about a damage emergence or human interference.

Thus, the new data processing systems should be able to store and organize all the collected information and process it. In other words, further than the numerical analysis tools improvement, computational systems, and data collecting systems implementation, it is necessary to define the information circle and optimization, until the platform's outputs, providing a more interactive and user-friendly platform for the owners or end users. Nevertheless, the technician's role during the structural assessment process should be sustained and adjusted. On most recent platforms' design and implementation, the wireless communication has been used [9, 92, 93], aiming at most "clean" and flexible monitoring system without cabling.

For HC monitoring, special care and attention should be given during the monitoring plan design and implementation. In fact, the less intrusive techniques should be employed to preserve the historical characteristics [100]. Thus, the durability parameters monitoring might be included to provide information about the damage emergences in the earliest age and, consequently, the maintenance measures can be minimized. However, for most real assessment, the building should be modeled considering its current state, including the damages already found. Beyond structural monitoring, the data collected should be correlated with data from visual inspection, photo and video, and information about human interference on HC. In any pre-defined limit overpassing, the responsible offices must be immediately contacted, including a specific alarm based on natural frequency changes. An automated monitoring system would perform periodic measurements of the natural frequencies, and in case of a change greater than a preestablished value, a signal alarm will be sent. In addition, reliability methods should be considered to provide most accurate answer about the structural safety.

The increasing advances on SHM have contributed for the broadening of the assessment process in a wide variety of structures [6, 35, 101]. With lower-cost systems development, SHM systems tend to be popularized [102] and integrated with other management systems, as security and comfort system, for instance. In this way, the current and future systems must be implemented optimizing the sensing system and the interaction with the available technologies, including older ones [103].

\section{Conclusions}

This work intended to review the employment of SHM systems for structural assessment, essentially related with dynamic monitoring. A short historical review on structural monitoring advances from 1993 to 2015, including the recent advances on sensors for SHM systems and some field implementation cases, was performed. In addition, recent damage detection methods based on modal response, especially focused on non-linear damages effects characterization, were also reported.

The state-of-the-art of the data processing systems was shown and its imminent necessity for implementation in this area, essentially systems and methods that offer an objective answer to owners on the structural safety should be developed. In addition, the construction material properties should also be reflected in the structural parameters.

A special consideration was given for SHM platforms. A benchmark report was carried out aiming to illustrate the 
current state-of-the-art, and was showed the necessity of development focused on the methods of data processing and platforms for structural assessment. Case studies reported in the literature were described and organized according with the method of classification for SHM platforms proposed in this work (an extension of the method developed by Rytter). The classification for SHM systems based in the answer level aims to provide a most objective orientation to owners, promoting the adequate selection of the monitoring system to install.

Sequentially, SHM case studies on HC were introduced, and the important system configurations were pointed. For $\mathrm{HC}$ monitoring, the systems should be very low intrusive (mechanically and visually) and the employment of the current technologies available (digital cameras, smartphones or tablets, for instance) can introduce an additional advantage to SHM: the possibility of recording and monitoring the human interference on the construction degradation. In addition, it was shown the necessity of implementation of studies, including full-scale structures and real structures, and, especially, the development and application of SHM techniques focused on HC.

Finally, Sect. 5 has shown that some areas should be most explored, namely: the optimization of the sensing systems with technological tools available, the interaction of the owners in the assessment process as an informative source about the day-by-day occurrences, in the integration of the SHM systems with others systems (smartphones, cameras, etc.).

The present work shown that the new sensors development is responsible by half of all innovation related with SHM field, and points to the necessity of SHM systems and platforms implementation. In addition, no SHM system or platforms are specifically addressed to $\mathrm{HC}$ issues, making it a great opportunity for the development of studies and innovation on SHM field, considering the high historical, social, and economical importance of $\mathrm{HC}$ for human societies.

In fact, $\mathrm{HC}$ are an interesting case for SHM development, because they impose the necessity of flexible and open SHM systems and platforms, allowing the possibility of performing changes on the sensorial system along time, all with very low intrusion. The development of tools for the safety maintenance support, in real time, can be an effective way to avoid dramatic losses, especially for monuments and constructions with visitors.

Acknowledgments This work was financially supported by: Project POCI-01-0145-FEDER-007457-CONSTRUCT-Institute of R\&D in Structures and Construction funded by the FEDER funds through COMPETE2020 - Programa Operacional Competitividade e Internacionalização (POCI) — and by the national funds through FCTFundação para a Ciência e a Tecnologia. Esequiel Mesquita acknowledge CAPES through the fellowship number 10023/13-5,
Fundação CAPES, Ministério da Educação do Brasil. Paulo Antunes acknowledge Fundação para a Ciência e a Tecnologia (FCT) for the post-doctoral fellowship SFRH/BPD/76735/2011.

\section{References}

1. Mehta K (2002) Greening of the concrete industry for sustainable development. Concr Int 24(7):23-28

2. Mehta K, Monteiro PJM (2008) Concreto: microestrutura, propriedades e materiais, 3rd edn. Pini, São Paulo

3. Milani G (2013) Lesson learned after the Emilia-Romagna, Italy, 20-29 May 2012 earthquakes: a limit analysis insight on three masonry churches. Eng Fail Anal 34:761-778

4. Zhu B, Frangopol DM (2013) Incorporation of structural health monitoring data on load effects in the reliability and redundancy assessment of ship cross-sections using Bayesian updating. Struct Health Monit 12(4):377-392

5. Omenzetter P, Brownjohn JMW, Moyo P (2004) Identification of unusual events in multi-channel bridge monitoring data. Mech Syst Signal Process 18(2):409-430

6. Okasha NM, Frangopol DM (2011) Computational platform for the integrated life-cycle management of highway bridges. Eng Struct 33(7):2145-2153

7. De Battista N, Brownjohn JMW, Tan HP, Koo K (2014) Measuring and modelling the thermal performance of the Tamar suspension bridge using a wireless sensor network. Struct Infrastruct Eng 11(2):176-193

8. Wu N, Liu C, Guo Y, Zhang J (2013) On-board computing for structural health monitoring with smart wireless sensors by modal identification using Hilbert-Huang transform. Math. Probl. Eng. 2013:1-9

9. Jang S, Spencer BF Jr, Sim S-H (2012) A decentralized receptance-based damage detection strategy for wireless smart sensors. Smart Mater Struct 21(5):055017

10. Fu TS (2009) Smart buildings: synergy in structural control, structural health monitoring and environmental systems. Ph.D. Thesis, University of Southern California

11. Munich RE (2012) TOPICS GEO Natural catastrophes 2011: Analyses, assessments, positions. Munich, Munich RE, Germany

12. Schumacher I, Strobl E (2011) Economic development and losses due to natural disasters: the role of hazard exposure. Ecol Econ 72:97-105

13. Zhengtang Z (2011) Natural catastrophe risk, insurance and economic development. Energy Procedia 5:2340-2345

14. Skoufias E (2003) Economic crises and natural disasters: coping strategies and policy implications. World Dev 31(7):1087-1102

15. United Nations (2012) The future we want in Rio+20 - United Nations Conference on Sustainable Development, Final Report. Rio de Janeiro

16. Helene P (2010) A nova NB 1/2003 (NBR 6118) e a vida útil das estruturas de concreto. Anais do $52^{\circ}$ Congresso Brasileiro do Concreto, vol. 2003, no. Nbr 6118, p 31

17. Shi X, Xie N, Fortune K, Gong J (2012) Durability of steel reinforced concrete in chloride environments: an overview. Constr Build Mater 30:125-138

18. Kovler K, Roussel N (2011) Properties of fresh and hardened concrete. Cem Concr Res 41(7):775-792

19. Pereira VCDO, Monteiro ECB, Almeida KDS (2013) Influence of cement type in reinforcement corrosion of mortars under action of chlorides. Constr Build Mater 40:710-718

20. Yoda K, Shintani A (2014) Building application of recycled aggregate concrete for upper-ground structural elements. Constr Build Mater 67:379-385 
21. Schmidt F, Rheinfurth M, Protz R, Horst P, Busse G, Gude M, Hufenbach W (2012) Monitoring of multiaxial fatigue damage evolution in impacted composite tubes using non-destructive evaluation. Compos Part A Appl Sci Manuf 43(3):537-546

22. Faifer M, Ferrara L, Ottoboni R, Toscani S (2013) Low frequency electrical and magnetic methods for non-destructive analysis of fiber dispersion in fiber reinforced cementitious composites: an overview. Sensors (Basel) 13(1):1300-1318

23. Rainieri C, Fabbrocino G, Verderame GM (2013) Non-destructive characterization and dynamic identification of a modern heritage building for serviceability seismic analyses. NDT E Int 60:17-31

24. de Assis WS (2007) Sistemas computacionais de apoio à monitoração de estruturas de engenharia civil. Ph.D. Thesis, University of São Paulo, São Paulo

25. Xia Y, Zhang P, Ni Y, Zhu H (2014) Deformation monitoring of a super-tall structure using real-time strain data. Eng Struct 67:29-38

26. Adams DE (2007) Health monitoring of structural materials and components: methods with applications, 1st edn. Wiley, Hoboken

27. Sohn H, Farrar CR, Hemez FM, Shunk DD, Stinemates DW, Nadler BR, Czarnecki JJ (2004) A review of structural health monitoring literature: 1996-2001. Los Alamos National Laboratory, USA

28. Brownjohn JMW (2007) Structural health monitoring of civil infrastructure. Philos Trans A Math Phys Eng Sci 365(1851):589-622

29. Doebling SW, Farrar CR, Prime MB (1997) A summary review of vibration-based damage identification methods. Los Alamos National Laboratory, Los Alamos

30. Lifshitz JM, Rotem A (1969) Determination of reinforcement unbonding of composites by a vibration technique. J Compos Mater 3:412-423

31. Rytter A (1993) Vibrational based inspection of civil engineering structures. Ph.D. Thesis, University of Aalborg, Aalborg

32. Sohn H (2007) Effects of environmental and operational variability on structural health monitoring. Philos Trans A Math Phys Eng Sci 365(1851):539-560

33. Jacques R, Clarke T, Morikawa S, Strohaecker T (2010) Monitoring the structural integrity of a flexible riser during dynamic loading with a combination of non-destructive testing methods. NDT E Int 43(6):501-506

34. Clayton EH (2006) Frequency correlation-based structural health monitoring with smart wireless sensors. Master's thesis, Civil Engineering Washingt. Univ., vol. 1, p 111

35. Kianian M, Golafshani AA, Ghodrati E (2013) Damage detection of offshore jacket structures using frequency domain selective measurements. J Mar Sci Appl 12(2):193-199

36. Gillich G-R, Praisach Z-I (2014) Modal identification and damage detection in beam-like structures using the power spectrum and time-frequency analysis. Signal Process 96:29-44

37. Doebling SW, Farrar CR, Prime MB, Shevitz DW (1996) Damage identification and health monitoring of structural and mechanical systems from changes in their vibration characteristics: A literature review, 1st edn. Los Alamos National Laboratory, Los Alamos

38. Ye XW, Su YH, Han JP (2014) Structural health monitoring of civil infrastructure using optical fiber sensing technology: a comprehensive review. Sci World J 2014:652329

39. Worden K, Farrar CR, Manson G, Park G (2007) The fundamental axioms of structural health monitoring. Proc $\mathrm{R}$ Soc London A Math Phys Eng Sci 463(2082):1639-1664

40. Farrar CR, Worden K (2007) An introduction to structural health monitoring. Philos Trans A Math Phys Eng Sci 365(1851):303-315
41. Wenzel H (2008) Health monitoring of bridges, 1st edn. Wiley, Chichester

42. Lynch JP, Loh KJ (2006) A summary review of wireless sensors and sensor networks for structural health monitoring. Shock Vib Dig 38(2):91-130

43. Rodrigues C, Félix C, Lage A, Figueiras J (2010) Development of a long-term monitoring system based on FBG sensors applied to concrete bridges. Eng Struct 32(8):1993-2002

44. Mita A, Sato H, Kameda H (2010) Platform for structural health monitoring of buildings utilizing smart sensors and advanced diagnosis tools. Struct Control Heal Monit 17(7):795-807

45. Antón O, Hidalgo R, Rivera R, Tomasel FG (2002) Simple swept-sine analyzer for excitation and measurement of dynamic response in ocean structures. Ocean Eng 29(10):1209-1217

46. Antunes P, Dias J, Paixão T, Mesquita E, Varum H, André P (2015) Liquid level gauge based in plastic optical fiber. Measurement 66:238-243

47. Antunes P, Rodrigues H, Travanca R, Ferreira L, Varum H, André P (2012) Structural health monitoring of different geometry structures with optical fiber sensors. Photonic Sensors 2(4):357-365

48. Esfandiari A, Bakhtiari-Nejad F, Rahai A (2013) Theoretical and experimental structural damage diagnosis method using natural frequencies through an improved sensitivity equation. Int J Mech Sci 70:79-89

49. Sim S-H, Carbonell-Márquez JF, Spencer BF, Jo H (2011) Decentralized random decrement technique for efficient data aggregation and system identification in wireless smart sensor networks. Probab Eng Mech 26(1):81-91

50. Trost SG, Mciver KL, Pate RR (2005) Conducting accelerometer-based activity assessments in field-based research. Med Sci Sport Exerc 3711:531-543

51. Wu J, Yuan S, Ji S, Zhou G, Wang Y, Wang Z (2010) Multiagent system design and evaluation for collaborative wireless sensor network in large structure health monitoring. Expert Syst Appl 37(3):2028-2036

52. Antunes P, Lima H, Varum H, André P (2012) Optical fiber sensors for static and dynamic health monitoring of civil engineering infrastructures: abode wall case study. Measurement 45(7):1695-1705

53. WIPO "World Intellectual Property Organization" (2014). http://www.wipo.int/portal/en/index.html. Accessed 14 Feb 2014

54. Chiorean CG (2013) A computer method for nonlinear inelastic analysis of 3D composite steel-concrete frame structures. Eng Struct 57:125-152

55. Nothwang WD, Hirsch SG, Demaree JD, Hubbard CW, Cole MW, Lin B, Giurgiutiu V (2006) Direct integration of thin film piezoelectric sensors with structural materials for structural health monitoring. Integr Ferroelectr 83(1):139-148

56. EPO, "European Patent Office" (2014) http://www.epo.org/. Accessed 15 Feb 2014

57. USPTO, "United States Patent and Trademark Office" (2014) http://www.uspto.gov/. Accessed 20 Feb 2014

58. McKeown B (2013) System, device and associated methods for monitoring a physical condition or operating performance of a structure. 20130132032

59. Graves Spencer B (2012) Software to facilitate design, data flow and decision support in structural health monitoring systems. US Patent 20120123981

60. Xiaodan S (2011) Integral and local information fusing method of structure health diagnosis. CN Patent CN102034021

61. Mathaeus D, Ciprian R, Cihan TN, Claus N (2011) Scalable and extensible framework for storing and analyzing sensor data. US Patent US20110035187 
62. Jeong-Beom I (2009) Virtual time reversal acoustics for structural health monitoring. US Patent US20090083004

63. Jeong-Beom I (2009) Method and apparatus for modeling responses for a material to various inputs. US Patent US20090048721

64. Peter KG (2007) System and method for optical sensor interrogation. US Patent 20070223003

65. Zhou L, Yan G, Wang L, Ou J (2013) Review of benchmark studies and guidelines for structural health monitoring. Adv Struct Eng 16(7):1187-1206

66. Johnson EA, Lam HF, Katafygiotis LS, Beck JL (2004) Phase I IASC-ASCE structural health monitoring benchmark problem using simulated data. J Eng Mech 130(1):3-15

67. Canada ISIS (2001) Guidelines for structural health monitoring, 1st edn. ISIS Canada, Winnipeg

68. Bergmeister K (2002) Monitoring and safety evaluation of existing concrete structures. fib fédération international du béton, Switzerland

69. Aktan A, Catbas F, Grimmelsman K, Pervizpour M (2002) Development of a model health monitoring guide for major bridges. Federal Highway Administration Research and Development Philadelphia (Report), Philadelphia

70. ISO (2004) Mechanical vibration-evaluation of measurement results from dynamic tests and investigations on bridges. ISO, Switzerland, p 26

71. Rucker W, Hille F, Rohrmann R (2006) Guideline for structural health monitoring, 1st edn. SAMCO, Berlin

72. Rücker PW, Hille DF, Rohrmann DR (2006) Guideline for assessment of existing structures, 1st edn. SAMCO, Berlin

73. Daum W (2013) Guidelines for structural health monitoring. In: Handbook of technical diagnostics, Springer, pp 539-541

74. Nichols JM (2003) Structural health monitoring of offshore structures using ambient excitation. Appl Ocean Res 25(3):101-114

75. Minakuchi S, Takeda N (2013) Recent advancement in optical fiber sensing for aerospace composite structures. Photonic Sensors 3(4):345-354

76. Lin X, Ren L, Xu Y, Chen N, Ju H, Liang J, He Z, Qu E, Hu B, Li Y (2014) Low-cost multipoint liquid-level sensor with plastic optical fiber. IEEE Photonics Technol Lett 26(16): 1613-1616

77. Brownjohn JMW, Magalhaes F, Caetano E, Cunha A (2010) Ambient vibration re-testing and operational modal analysis of the Humber bridge. Eng Struct 32(8):2003-2018

78. Magalhães F, Cunha A, Caetano E (2012) Vibration based structural health monitoring of an arch bridge: from automated OMA to damage detection. Mech Syst Signal Process 28:212-228

79. Martins N, Caetano E, Diord S, Magalhães F, Cunha Á (2014) Dynamic monitoring of a stadium suspension roof: wind and temperature influence on modal parameters and structural response. Eng Struct 59:80-94

80. Razi P, Esmaeel RA, Taheri F (2013) Improvement of a vibration-based damage detection approach for health monitoring of bolted flange joints in pipelines. Struct Heal Monit 12(3):207-224

81. Bandara RP, Chan TH, Thambiratnam DP (2014) Structural damage detection method using frequency response functions. Struct Heal Monit 13(4):418-429

82. Nie Z, Hao H, Ma H (2012) Using vibration phase space topology changes for structural damage detection. Struct Heal Monit 11(5):538-557

83. Naghashpour A, Van Hoa S (2014) A technique for real-time detecting, locating, and quantifying damage in large polymer composite structures made of carbon fibers and carbon nanotube networks. Struct Heal Monit 14(1):35-45
84. D'Alessandro A, Ubertini F, Materazzi AL, Laflamme S, Porfiri M (2015) Electromechanical modelling of a new class of nanocomposite cement-based sensors for structural health monitoring. Struct Heal Monit 14(2):137-147

85. Hosser D, Klinzmann C, Schnetgöke R (2008) A framework for reliability-based system assessment based on structural health monitoring. Struct Infrastruct Eng 4(4):271-285

86. Yi T, Li H, Gu M (2010) Full-scale measurements of dynamic response of suspension bridge subjected to environmental loads using GPS technology. Sci China Technol Sci 53(2):469-479

87. Zhang W, Gao J, Shi B, Cui H, Zhu H (2006) Health monitoring of rehabilitated concrete bridges using distributed optical fiber sensing. Comput Civ Infrastruct Eng 21:411-424

88. Ni YQ, Wong KY (2012) Integrating bridge structural health monitoring and condition-based maintenance management. In: Civil Structural Health Monitoring Workshop (CSHM-4). ISHMII, Berlin

89. Guo T, Li A, Wang H (2008) Influence of ambient temperature on the fatigue damage of welded bridge decks. Int $\mathbf{J}$ Fatigue 30(6): 1092-1102

90. CIB (2010) Guide for the structural rehabilitation of heritage buildings, 1st edn. CIB, Rotterdam

91. Tavares A, Costa A, Varum H (2014) Manual de manutenção de edifícios em adobe, 1 st edn, vol 24, no 4. Publindústria, Aveiro

92. Abruzzese D, Angelaccio M, Giuliano R, Miccoli L, Vari A (2009) Monitoring and vibration risk assessment in cultural heritage via wireless sensors network. In: 2009 2nd Conf Hum Syst Interact, pp 568-573, May 2009

93. Bencini L, Collodi G, Di Palma D, Manes G, Manes A (2010) An embedded wireless sensor network system for cultural heritage monitoring. In: 2010 Fourth Int Conf Sens Technol Appl, pp 185-190, Jul. 2010

94. Balsamo D, Paci G, Benini L, Davide B (2013) Long term, low cost, passive environmental monitoring of heritage buildings for energy efficiency retrofitting. In: 2013 IEEE Work Environ Energy Struct Monit Syst, pp 1-6, Sep. 2013

95. Lima HF, Vicente RDS, Nogueira RN, Abe I, Andre PSDB, Fernandes C, Rodrigues H, Varum H, Kalinowski HJ, Costa A, Pinto JDL (2008) Structural health monitoring of the church of Santa Casa da Misericórdia of Aveiro using FBG sensors. IEEE Sens J 8(7):1236-1242

96. Costa A, Arêde A, Paupério E, Romão X (2014) Reabilitação estrutural: casos práticos de intervenção em estruturas patrimoniais, 1st edn. Universidade do Porto, Porto

97. Kostecki R, Ebendorff-Heidepriem H, Warren-Smith SC, McAdam G, Davis C, Monro TM (2013) Optical fibres for distributed corrosion sensing-architecture and characterisation. Key Eng Mater 558:522-533

98. Antunes P, Varum H, André P (2011) Uniaxial fiber Bragg grating accelerometer system with temperature and cross axis insensitivity. Measurement 44(1):55-59

99. Betz DC, Thursby G, Culshaw B (2015) Structural damage location with fiber Bragg grating rosettes and lamb waves. Struct Health Monit 6(4):299-308

100. Kurata N, Spencer BF, Ruiz-Sandoval M (2005) Risk monitoring of buildings with wireless sensor networks. Struct Control Heal Monit 12(3-4):315-327

101. Barbosa C, Costa N, Ferreira LA, Araújo FM, Varum H, Costa A, Fernandes C, Rodrigues H (2008) Weldable fibre Bragg grating sensors for steel bridge monitoring. Meas Sci Technol 19(12): 125305

102. Isidori D (2013) A low-cost structural health monitoring system for residential buildings: experimental tests on a scale model. $\mathrm{Ph} . \mathrm{D}$. Thesis, Università Politecnica Delle Marche, Ancona

103. Wu L-J, Casciati F, Casciati S (2014) Dynamic testing of a laboratory model via vision-based sensing. Eng Struct 60:113-125 